\title{
Burning Characteristics of Fuel Droplet from Refined Lubricating Oil
}

\author{
Fang-Cih Lee ${ }^{1}$, Fang-Hsien Wu ${ }^{2}$, Guan-Bang Chen ${ }^{2}$, Chang-Jui Huang ${ }^{2}$, Yei-Chin Chao ${ }^{1}$ \\ 1 Department of Aeronautics and Astronautics, National Cheng Kung University \\ ${ }^{2}$ Research Center for Energy Technology and Strategy, National Cheng Kung University \\ *Corresponding author email: gbchen@mail.ncku.edu.tw
}

\begin{abstract}
The burning characteristics of heavy fuel oil (HFO) and two types of refined lubricating oil (RLO) with different filtration condition are studied using TGA-FTIR analysis and a suspended droplet system. In comparison with HFO, RLO has more volatile composition, larger oxidation rate and lower gas emissions. RLO also lower ignition temperature and burnout temperature. The oxidation activation energies of these three oils were also calculated by Flynn-WallOzawa method and both refined lubricating oils have similar activation energy. HFO has a higher activation energy especially when the conversion rate exceeds $40 \%$. The results of suspended droplet experiments show that the combustion rate and the micro-explosion performance of RLO are more intense than these of HFO. During the combustion process, all these oils follow $d^{2}$-law. The magnitude of the combustion rate is RLO_B>RLO_A $>$ HFO and the final residual amount is HFO $>\mathrm{RLO} \_\mathrm{B}>\mathrm{RLO} \_\mathrm{A}$. In general, RLB_O has the best combustion performance among these oils.
\end{abstract}

\section{Keywords}

Burning characteristics, Refined lubricating oil, Suspended droplet system, Micro-explosion.

\section{Introduction}

Lubricating oil is used on all kinds of machinery to reduce friction and protect parts. It mainly plays the role of lubrication, cooling, rust prevention, cleaning, sealing and buffering. After a certain period of use, these lubricating oils will be contaminated by impurities such as air, water, dust, metals produced from mechanical parts, and even deteriorate. Therefore, the lubricating oil must be replaced in time. The replaced oil is generally called waste lubricating oil. Waste lubricating oil has the dual characteristics of pollution and resources. Improper treatment of waste lubricating oil will cause serious environmental problems, but reasonable recycling can become a valuable resource. Many lubricating oils contain heavy metal salt additives, chlorine, sulfur, phosphorus and other organic compounds. In the process of use, due to the high temperature environment or the catalytic oxidation of impurities, it often contains a variety of toxic chemicals and heavy metals, which will cause serious pollution to the soil.

The lubricating oil is mainly derived from petroleum (a mixture of $80 \% \sim 90 \%$ base oil and 10\% 20\% additives) and fossil fuels are exhaustive and non-renewable. Waste lubricating oil has high reuse value and can be regenerated into base oil, fuel oil, diesel and other products through suitable regeneration technology. In addition, it is more economical to use waste lubricating oil to refine regenerated lubricating oil, which can effectively reduce raw material costs and refining costs. If the lower grade waste lubricating oil can be further refined into fuel oil, it can replace traditional heavy oil. Refined fuel oil refers to the fuel oil obtained after pretreatment, catalytic cracking, rectification, condensation, slag removal, decolorization and filtration of waste lubricating oil. The advantages of using refined lubricating oil as fuel oil include: 1. reducing the pollution caused by the discharge of waste lubricants. 2. High calorific value, low viscosity and good atomization effect. 3.substitue of heavy fuel oil. 4. easy storage and use for a long time.

There was a study in the literature that systematically evaluate waste lubricating oils as 
energy fuels [1]. Kanokkantapong et al. [2] made six assessments of waste lubricating oil based on the life cycle method, including technical aspects and environmental impacts. Singhabhandhu et al. [3] evaluated the benefits and costs of two energy replacement systems (waste cooking oil and waste lubricating oil) and the results showed that the system composed of waste cooking oil and waste lubricating oil is a advantageous alternative to the management of waste lubricating oil. Singhabhandhu et al. [4] evaluated the resource utilization of waste lubricating oil, waste cooking oil and waste plastics, and analyzed the cost of electricity and transportation. Their results showed that from the perspective of energy acquisition and economics, simultaneous treatment of the three wastes will have the greatest benefit. Hsu and Liu [5] used analytic hierarchy process to analyze, compare and select waste lubricating oil, providing a research basis for manufacturers to select waste lubricating oil regeneration methods.

Kim et al. used thermogravimetric analyzer to study the non-isothermal pyrolysis characteristics of waste automobile lubricating oil in a stirred batch reactor [6]. Kim et al. studied the kinetics and absorption characteristics of tar formation from pyrolysis of waste lubricating oil [7]. They constructed a simplified functional kinetic model for the formation of tar. Kim et al. studied the pyrolysis kinetics and characteristics of the mixtures of waste ship lubricating oil and waste fishing rope at different heating rates [8]. Fuentes et al. used thermogravimetric analysis to study the pyrolysis and combustion of waste lubricant oil from diesel cars at different $\mathrm{N}_{2} / \mathrm{O}_{2}$ ratios, different masses and different heating rates [9]. In the literature, the research concerning the burning characteristics of refined lubricating oil is still rare. Therefore, in this study, a thermogravimetric analysis integrated with Fourier transform infrared spectroscopy and a single suspended droplet system are used to explore the burning characteristics of refined lubricating oil.

\section{Material and Methods}

Two kinds of refined lubricating oil used in the study are provided by a commercial company and they are labeled as RLO_A and RLO_B. The waste lubricating oil mainly comes from steel factories and screw factories. The basic regeneration steps are to heat, stir and filter the waste lubricating oil to remove water, suspended matter and metal impurities. Based on the filtration degree, it can be divided into the oil with the low filtration degree called RLO_A and the oil with the high filtration degree called RLO_B. Compared with HFO, RLO has similar heating value, but better fluidity. Figure 1 shows the images of heavy fuel oil and two refined lubricating oils.

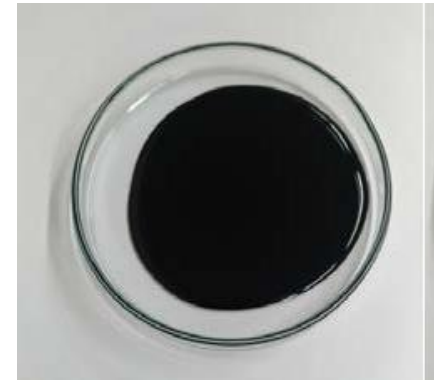

(a)

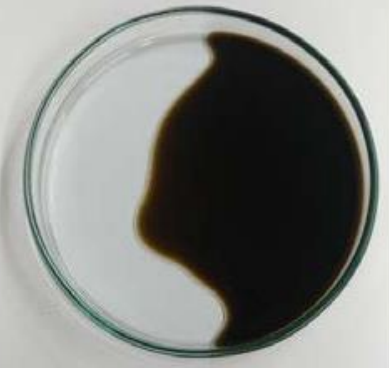

(b)

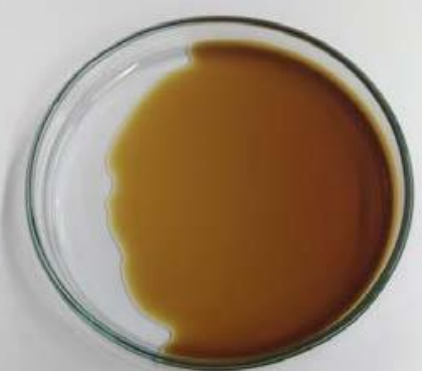

(c)

Figure 1. Images of (a)HFO (b)RLO_A (c)RLO_B.

\subsection{TG-FTIR Analysis}

The weight loss history and exothermic phenomenon of the refined lubricating oil in a linearly heated environment were investigated using a thermal analyser (PerkinElmer STA 8000) which was coupled with a differential scanning calorimetry (DSC) to measure the heat flow into or out of the sample over time. Evolved gas products in the TGA experiments were analyzed using a Fourier transform infrared spectrometer (PerkinEImer Spectrum Two FT-IR). 
The transfer pipe and the gas cell in the FTIR were both heated at a constant temperature of $280^{\circ} \mathrm{C}$ to prevent gas condensation and minimize secondary reactions. The samples weight was $(10 \pm 0.5) \mathrm{mg}$ and heated from $30^{\circ} \mathrm{C}$ to $900^{\circ} \mathrm{C}$ at $20^{\circ} \mathrm{C} / \mathrm{min}$ under air flowing rate of 80 $\mathrm{mL} / \mathrm{min}$.

\subsection{Suspended Droplet Experimental System}

The suspended drop method is commonly used in the study of single droplet ignition and combustion [10-12]. The experimental setup for a single suspended droplet is shown in Figure 2. It consists of a droplet suspension and movement system (numbers 1, 2, 5), heating device that can control temperature (numbers 3,4 ), temperature recording system (numbers 5, 6, 7), image recording system (numbers $8,9,10$ ) and the temperature and image data synchronization system (numbers 9, 11, 12). The main function of the droplet suspension and movement system is to suspend the droplet on the K-type thermocouple and to drive the droplet in and out of the thermal environment with a constant speed using a group of AC motors. The heating device is composed of two heating plates placed in parallel with a distance of $9 \mathrm{~mm}$. The output power is adjusted to control the temperature of the heating plates and keep it at the target temperature. The change in ambient temperature is measured by another K-type thermocouple. The ambient temperature will be increased from room temperature to the setting temperature $\left(600^{\circ} \mathrm{C}\right)$. The experiments are started when the heating plates are heated to attain the target temperature. When the thermocouple was in the preset position, the motorized stage would touch the switch, and simultaneously triggered the high- speed camera (Cooke: PCO.1200hs) and the data acquisition system (DAQ, National Instrument: BNC-2110) for image and signal recording.

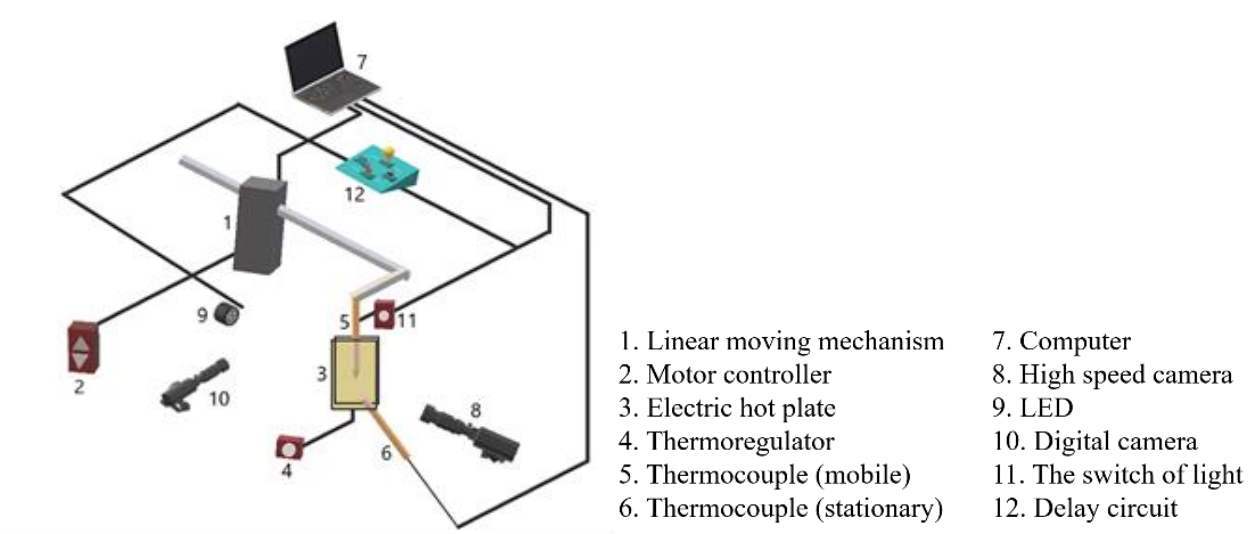

Figure 2. The schematic of suspended droplet experimental system

\section{Results and Discussion}

\subsection{Thermogravimetric Analysis (TGA)}

Figure 3 shows the oxidation profiles of thermogravimetric analysis for HFO and two kinds of refined lubricating oils. There are two stages for the weight loss curve for heavy fuel oil. The first stage is volatile decomposition and combustion stage at the temperature between 194 ${ }^{\circ} \mathrm{C}$ and $529^{\circ} \mathrm{C}$. The maximum weight loss occurs at $410^{\circ} \mathrm{C}$. The second stage is the combustion stage of heavy weight components at the temperature between $529^{\circ} \mathrm{C} \sim 674^{\circ} \mathrm{C}$. As to the refined lubricating oils, the weight loss curve of RLO_A shows that its primary weight loss occurs between $200^{\circ} \mathrm{C}$ and $433^{\circ} \mathrm{C}$, and the DTG curve has a peak at $352^{\circ} \mathrm{C}$. For RLO_B, its weight loss curve also has two stages and the first one occurs between 200 ${ }^{\circ} \mathrm{C}$ and $409^{\circ} \mathrm{C}$ with the maximum weight loss rate at $341^{\circ} \mathrm{C}$. The second stage is weaker than fist stage and the maximum reaction rate occurs at about $557^{\circ} \mathrm{C}$. From Figure 3 , it is also found that ignition temperatures and burnout temperatures of RLO are lower than those of the HFO. The maximum weight loss rate of RLO is larger than that of the HFO. In addition, from the DTG curves, it can be inferred that the composition of HFO is more complicated 


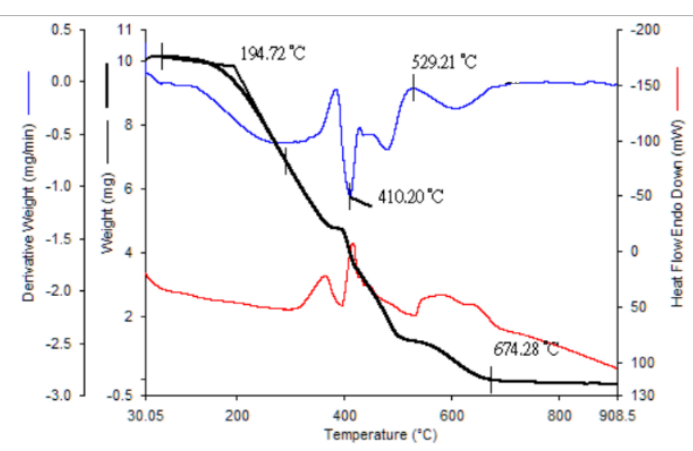

(a)

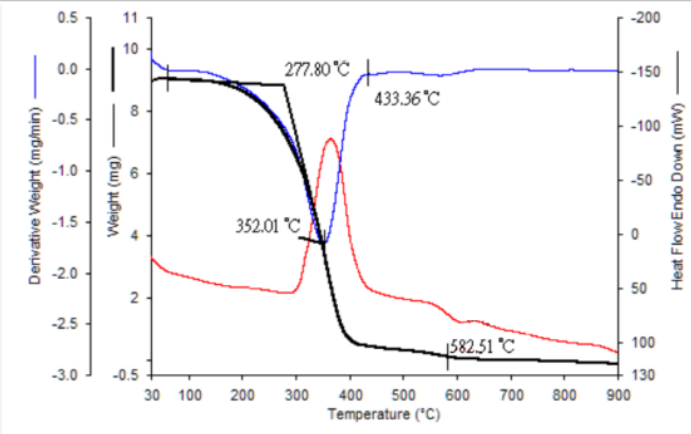

(b)

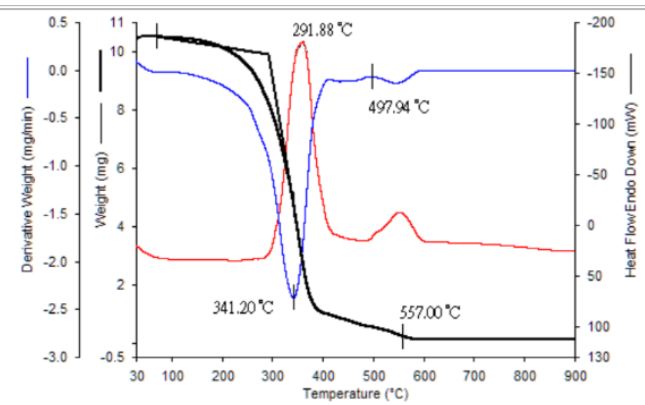

(c)

Figure 3 Thermogravimetric analysis of (a)HFO (b)RLO_A (c)RLO_B

\section{3-2. Fourier Transform Infrared Spectroscopy (FTIR)}

Figure 4 shows a 3D image of the FTIR signal for the oxidation process of HFO, RLO_A and RLO_B. The difference between the two refined lubricating oils is not great, but the position, intensity, peak shape and time of the infrared absorption peaks for these three fuels are significantly different. It is obvious that the peak of HFO appears later. The refined lubricating oils have fewer peaks and lower peak intensity. The heavy oil has more peaks, strong peak intensity and longer duration

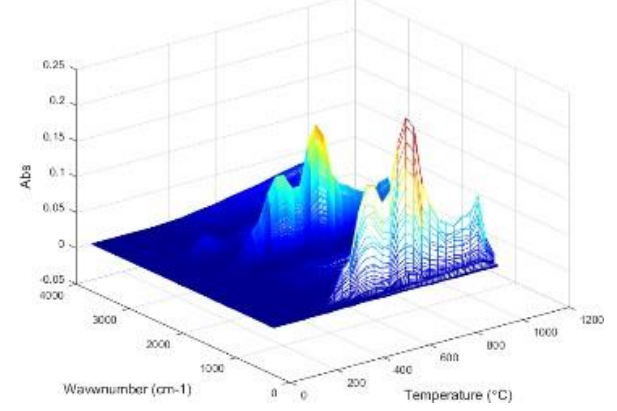

(a)

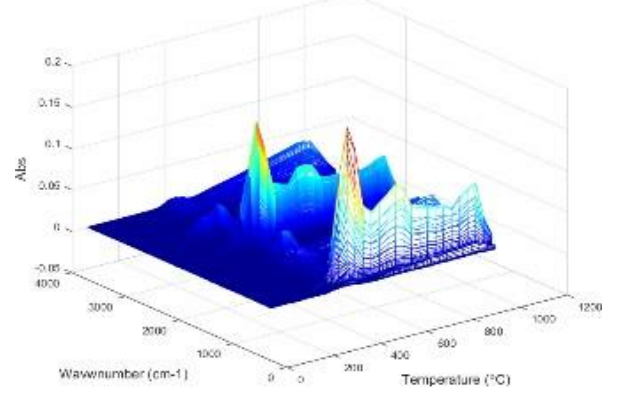

(b)

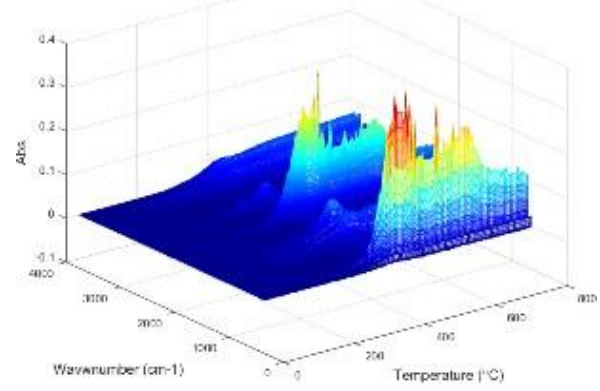

(c)

Figure 4 3D FTIR signals of (a) HFO (b) RLO_A and (c)RLO_B 
Figure 5 shows FTIR spectrum of three oils in the temperatures of $210^{\circ} \mathrm{C}, 412^{\circ} \mathrm{C}$ and $515^{\circ} \mathrm{C}$. In the study, the studied gases $\left(\mathrm{H}_{2} \mathrm{O}, \mathrm{CO}, \mathrm{CO}_{2}, \mathrm{NO}_{x}\right.$, and $\left.\mathrm{SO}_{\mathrm{x}}\right)$ and their wavenumber intervals are described as follows: The characteristic wavenumber of $\mathrm{CO}_{2}$ is $2360 \mathrm{~cm}^{-1}$, the characteristic wavenumber of $\mathrm{H}_{2} \mathrm{O}$ is between $1500 \sim 1700 \mathrm{~cm}^{-1}$. For $\mathrm{CO}$, two characteristic wavenumbers are $3400 \sim 3725 \mathrm{~cm}^{-1}$ and $2073 \mathrm{~cm}^{-1}$. For $\mathrm{NO}_{\mathrm{x}}$ and $\mathrm{SO}_{\mathrm{x}}$, the corresponding characteristic wavenumbers are $1762 \mathrm{~cm}^{-1}$ and $1338 \sim 1377 \mathrm{~cm}^{-1}$, respectively. From the intensity of the absorption peak, it can be inferred that the $\mathrm{CO}_{2}$ produced from the oxidation of $\mathrm{RLO} B \mathrm{~B}$ is the highest among these three oils and the $\mathrm{NO}_{\mathrm{x}}$ and $\mathrm{SO}_{\mathrm{x}}$ produced from the oxidation of RLO is lower than HFO.

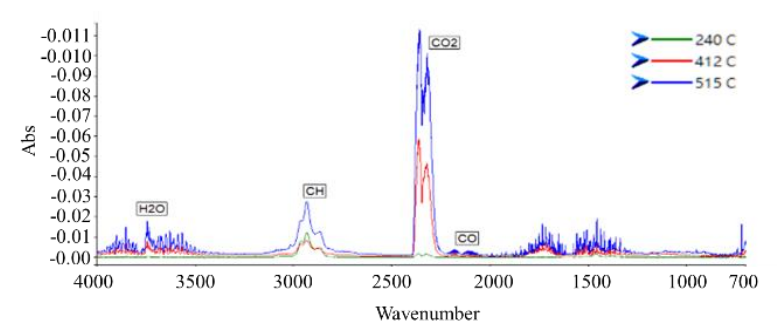

(a)

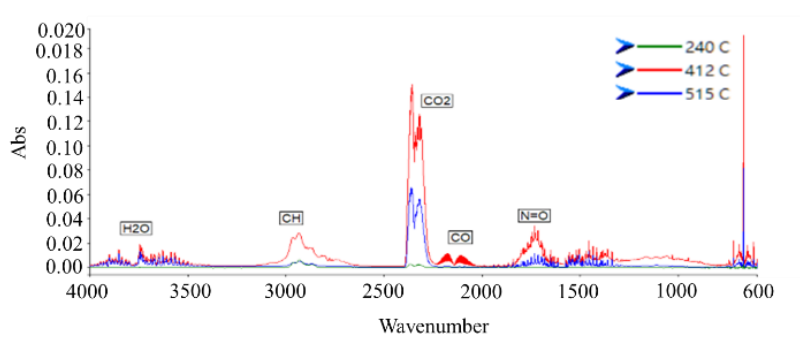

(b)

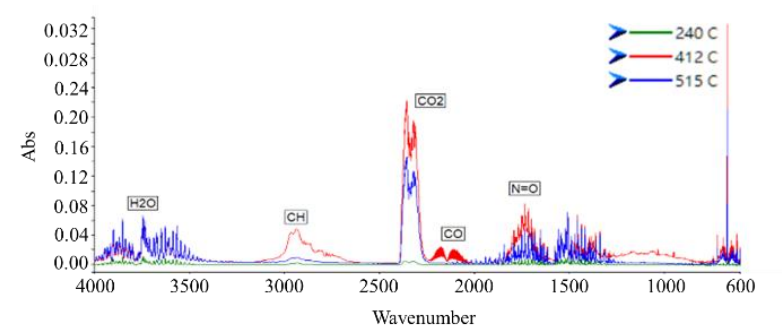

(c)

Figure 5 FTIR spectrum of (a) HFO (b) RLO_A (c) RLO_B at three temperatures

\section{3-3. The activation energy analysis by Flynn-Wall-Ozawa method}

Figure 6 shows the oxidation activation energy calculated by Flynn-Wall-Ozawa method [13] for different oils. the correlation coefficient of the dotted line is less than 0.97 and it is too low to be considered. The activation energy of all these oils increases gradually. As the oil evaporated and violently reacts with the oxidizer, the reaction products spread out rapidly. After that, the surface temperature of the droplet increases and the heavyweight components can be further burned, which have a higher activation energy. During the combustion process, the activation energy of RLO_A is in the range of $70 \sim 90 \mathrm{~kJ} / \mathrm{kmol}$. The activation energy of $\mathrm{RLO} B$ is in the range of $80 \sim 100 \mathrm{~kJ} / \mathrm{kmole}$. At $30 \%$ reconversion rate of HFO, the activation energy is about $79 \mathrm{~kJ} / \mathrm{kmol}$. At $50 \%$ conversion rate, the activation energy is as high as $162 \mathrm{~kJ} / \mathrm{kmol}$.

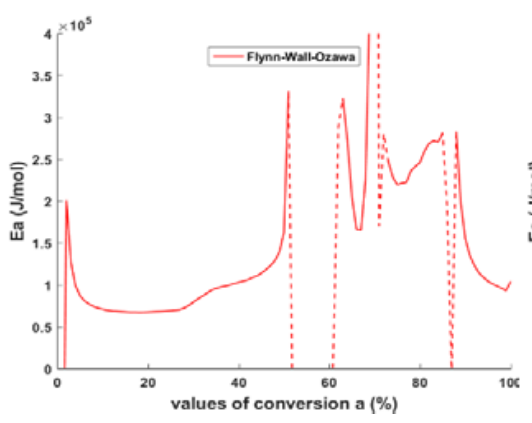

(a)

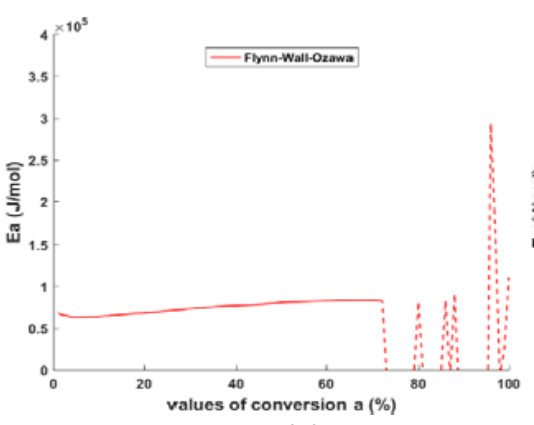

(b)

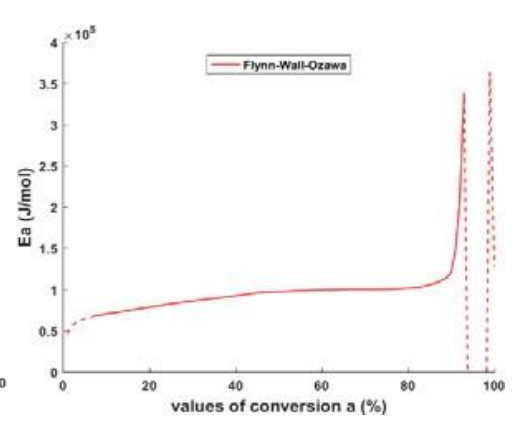

(c)

Figure 6 The activation energy of (a) HFO (b) RLO_A (c) RLO_B 


\section{3-4. Suspended droplet experiments}

In this study, single droplet heating experiments were performed at four different temperatures $\left(300^{\circ} \mathrm{C}, 400^{\circ} \mathrm{C}, 500^{\circ} \mathrm{C}\right.$, and $\left.600^{\circ} \mathrm{C}\right)$. The heating process of the droplet can be divided into six conditions: A. Expansion B. Micro-explosion C. Combustion expansion D. Combustion micro-explosion $\mathrm{E}$. char combustion F. residue. When the ambient temperature is $300^{\circ} \mathrm{C}$, the three kinds of oil only slightly expand. When the ambient temperature is $400^{\circ} \mathrm{C}$ or $500^{\circ} \mathrm{C}$, the three kinds of oil all have micro-explosion. When the ambient temperature reaches $600^{\circ} \mathrm{C}$, all six kinds of heating phenomena appear.

Figure 7 depicts the results for the suspended droplet experiment for these three oils at an ambient temperature of $600^{\circ} \mathrm{C}$. RLO_B has the most intense micro-explosion and droplet rupture among these oils. The flammable mixture forms a flame wrapping around droplets after it is ignited in high temperature environments. During the droplet combustion process, the micro-explosion occurs continuously; however, the droplet still maintains the sphere-like appearance. According to the $\mathrm{d}^{2}$-law, which describes the droplet evaporation and combustion model, the square of droplet diameter in the combustion process changes linearly with time [14],

$$
\left(d / d_{0}\right)^{2}=1-\left(K / d_{0}^{2}\right) t
$$

Where $\mathrm{d}$ is the diameter of the droplet at $\mathrm{t}$; do is the initial diameter of the droplet; $\mathrm{K}$ is the combustion rate constant of the droplet. Figure 8 shows a curve fitting of droplet size $\left(\mathrm{d} / \mathrm{d}_{0}\right)^{2}$ variation and its slope at ambient temperature of $600^{\circ} \mathrm{C}$ for these three oils in the $\mathrm{C}, \mathrm{D}, \mathrm{E}$ regions of Figure 7, which show the combustion process. As show in Figure 8, the curve can be approximated using a straight line and the slope $\mathrm{K}$, which denotes the combustion rate constant, is approximately $0.96 \mathrm{~mm}^{2} / \mathrm{s}$ for HFO, $2.67 \mathrm{~mm}^{2} / \mathrm{s}$ for RLO_A and $8.74 \mathrm{~mm}^{2} / \mathrm{s}$ for RLO_B.

During the droplet combustion process, the micro-explosion occurs continuously. From Figure 7 and Figure 8, it can be found that the phenomenon of micro-explosion in RLO is more intense than HFO. It is inferred that the heavyweight components of RLO is relatively less. Therefore, when the RLO is heated, the convection and heat transfer of the internal liquid is stronger. In addition, evaporation and accumulation of pressure occurs inside the droplet. When the pressure inside the droplet is larger than the surface tension, it causes micro-explosion and ejection. At the end of the combustion process, residues of RLO at the thermocouple junction is less and it means the combustion is more complete. Finally, the final residual amount is HFO>RLO_B $>$ RLO_A. The magnitude of the combustion rate is RLO_B $>$ RLO_A $>$ HFO.

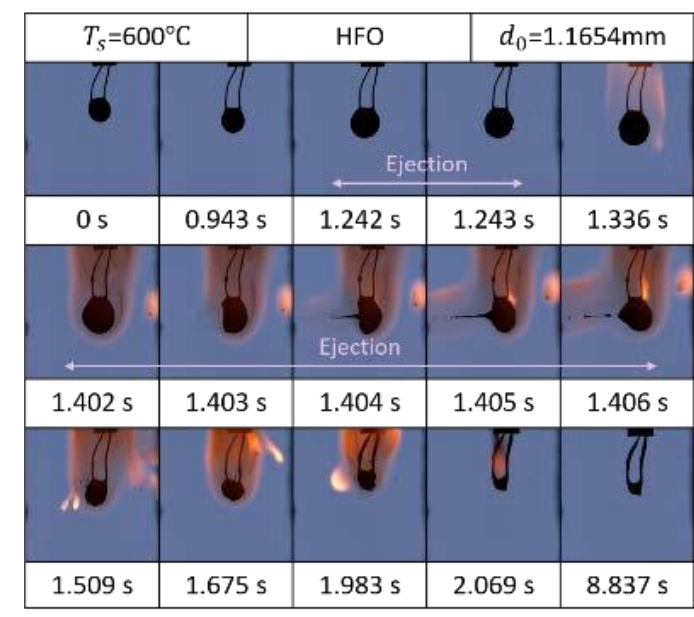

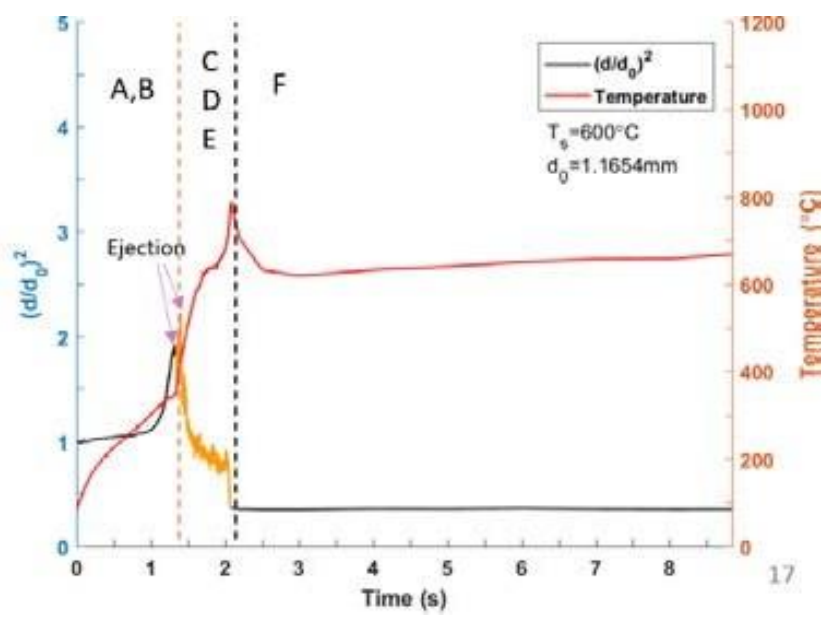

(a) 
ICLASS 2021, 15 th Triennial International Conference on Liquid Atomization and Spray Systems, Edinburgh, UK, 29 Aug. - 2 Sept. 2021
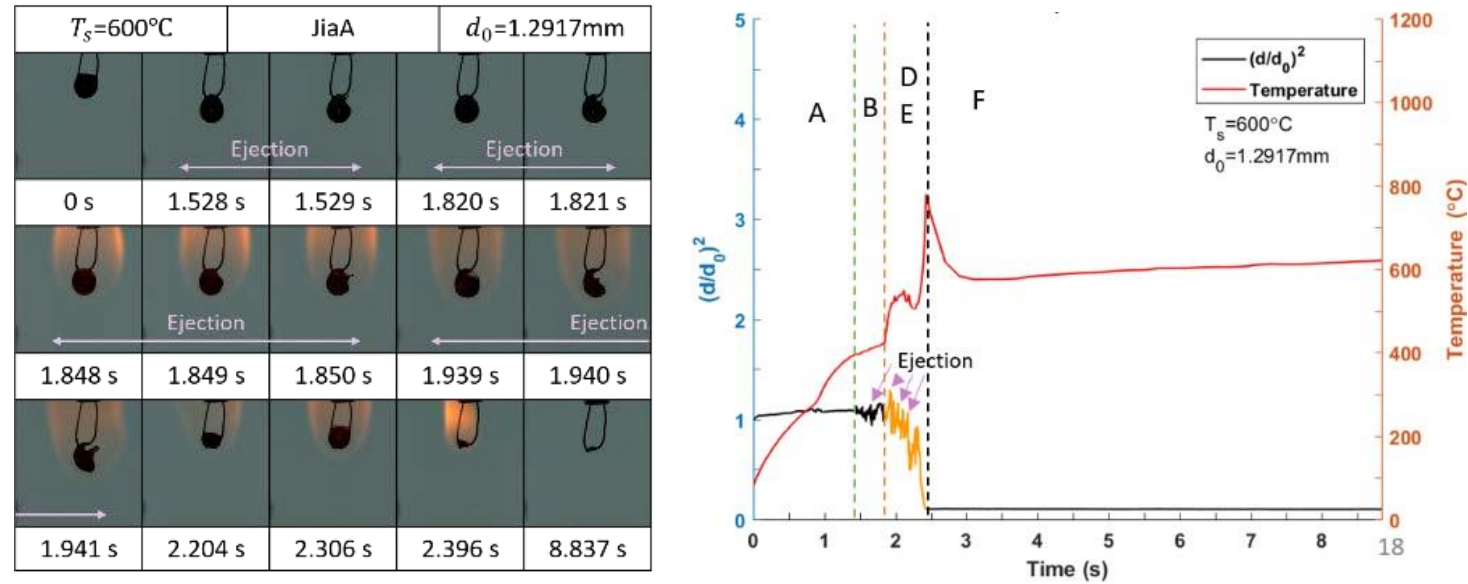

(b)
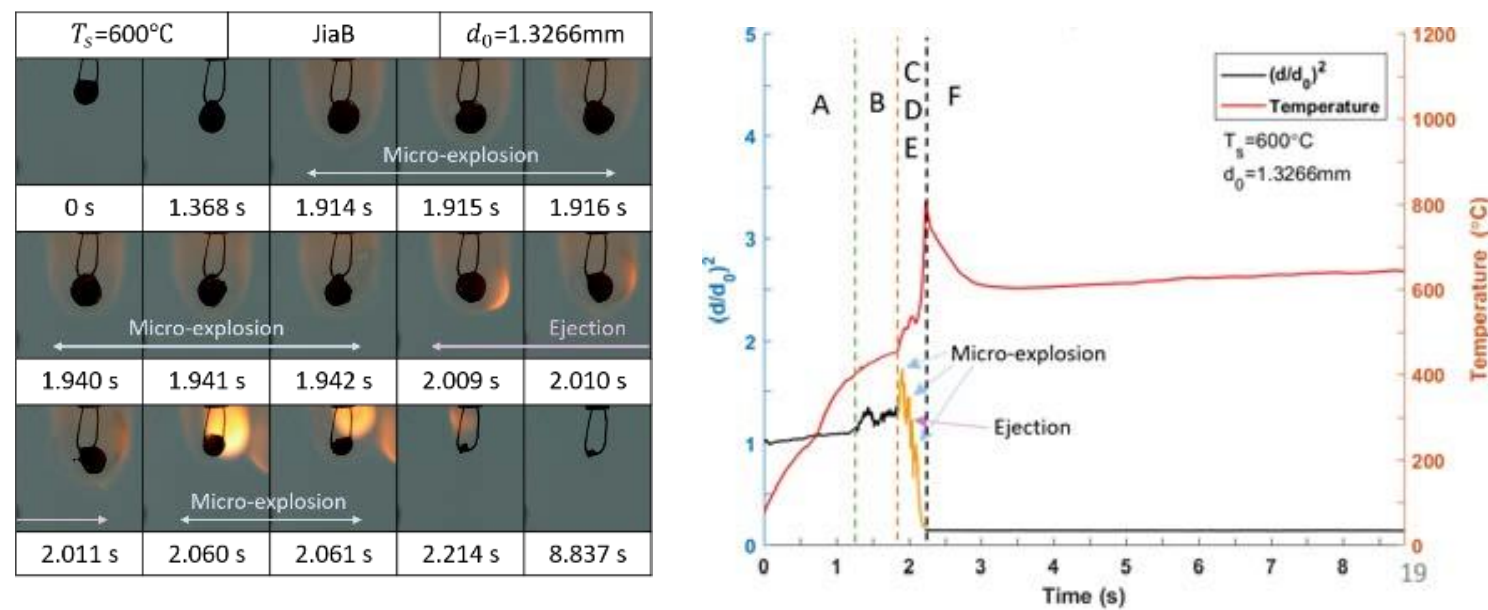

(c)

Figure 7 the combustion process of droplets of (a) HFO (b) RLO_A and (c)RLO_B at $600^{\circ} \mathrm{C}$

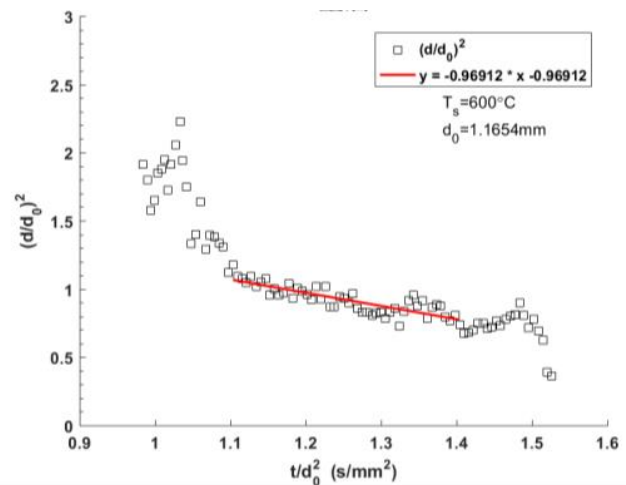

(a)

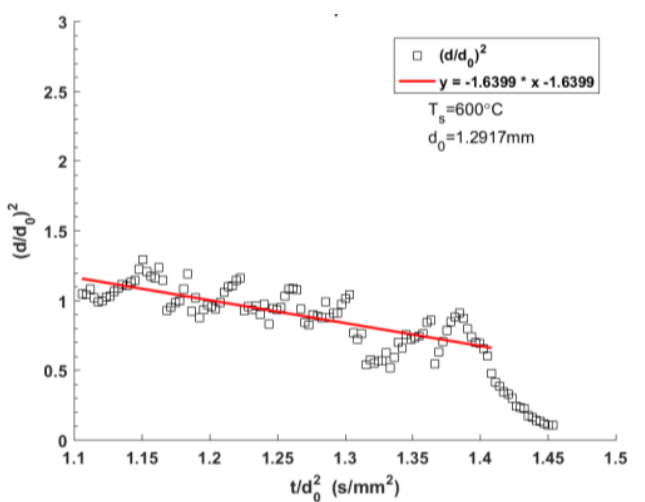

(b)

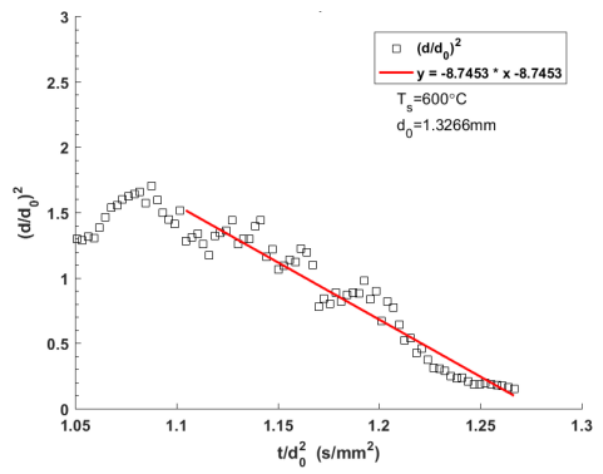

(c)

Figure 8 The relationship between $\left(d / d_{0}\right)^{2}$ and the time $\left(t / d_{0}{ }^{2}\right)$ of (a) HFO (b) RLO_A (c) RLO_B 
From Figure 7 and Figure 8, it can be found that the phenomenon of micro-explosion in RLO is more intense than HFO. It is inferred that the heavyweight components of RLO is relatively less. Therefore, when the RLO is heated, the convection and heat transfer of the internal liquid is stronger. In addition, evaporation and accumulation of pressure occurs inside the droplet. When the pressure inside the droplet is larger than the surface tension, it causes microexplosion and ejection. At the end of the combustion process, residues of RLO at the thermocouple junction is less and it means the combustion is more complete. Finally, the final residual amount is HFO $>\mathrm{RLO} B \mathrm{~B}>\mathrm{RLO}$ _A. The magnitude of the combustion rate is RLO_B $>$ RLO_A $>$ HFO.

\section{Conclusions}

In the study, the burning characteristics of HFO and two different RLO were investigated using TG-FTIR and a suspended droplet system. The result of TGA shows that RLO has more volatile decomposition and lower ignition temperature and burnout temperature when compared to HFO. The oxidation of RLO also has higher oxidation rate and emits lower $\mathrm{NO}_{\mathrm{x}}$ and $\mathrm{SO}_{\mathrm{x}}$. HFO has a higher oxidation activation energy. For the suspended droplet experiments, the micro- explosion effect of RLO is greater than HFO and the residual amount is less. At $600^{\circ} \mathrm{C}$, the combustion characteristics of all these oils follow $\mathrm{d}^{2}$-law and RLO_B has the largest combustion rate. Generally, it can be concluded that refined waste lubricating oil are a good substitute for heavy fuel oil no matter in environmental protection or combustion efficiency.

\section{References}

[1] Guerin, T. F., 2008, Journal of Hazardous Materials, 160(2),pp. 256-264.

[2] Kanokkantapong, V., Kiatkittipong W., Panyapinyopol B., Wongsuchoto P., Pavasant P., 2009, Resources Conservation and Recycling, 53(5), pp. 294-299.

[3] Singhabhandhu, A. and Tezuka T., 2010, Energy, 35(6), pp. 2493-2504.

[4] Singhabhandhu, A. and Tezuka T., 2010, Energy, 35(6), pp. 2544-2551.

[5] Hsu, Y. L. and C. Liu, 2011, Environmental monitoring and assessment, 176, pp. 197212.

[6] Kim, S. S., Chun B. H., and Kim S. H., 2003, Chemical Engineering Journal, 93(3), pp. 225-231.

[7] Kim, Y. S., Jeong S. U., Yoon W. L. Yoon H. K. Kin S. H., 2003, Journal of Analytical and Applied Pyrolysis, 70(1), pp. 19-33.

[8] Kim S. H., Kim S. S., Chun B. H., Jeon J.K., 2005, Korean Journal of Chemical Engineering, 22, pp. 573-578.

[9] Fuentes, M. J., Font R., Gómez-Rico M. F., Martín-Gullón I., 2007, Journal of Analytical and Applied Pyrolysis, 79(1), pp. 215-226.

[10] Lam, S. C. A. and Sobiesiak, A., 2006, Journal of Kones Powertrain and Transport, 13 (2) pp. 267-274.

[11] Wardana I. N. G., 2010, Fuel, 89, pp. 659-664.

[12] Hou S. S., Rizal F. M., Lin T. H., Yang T. Y., Wan H. P., 2013, Fuel, 113, pp. 31-42.

[13] Zhang, Y., Kang, L., Li H., Huang, X., Liu, X., Guo, L., Huang, L., 2019, Bioresource Technology, 288, pp. 121516.

[14] Spalding D. I., 1953, Fuel, 32, pp.169-185. 